\title{
Quantification of $T$ cell receptor rearrangement excision circles to estimate thymic function: an important new tool for endocrine-immune physiology
}

\author{
V Geenen, J-F Poulin ${ }^{1,2}$, M L Dion ${ }^{1,3}$, H Martens, E Castermans, \\ I Hansenne, M Moutschen, R P Sékaly ${ }^{1,4}$ and R Cheynier ${ }^{1}$ \\ University of Liege Centre of Immunology, Institute of Pathology CHU-B23, Department of Medicine, Division of Endocrinology, CHU-B35, B-4000 Liege-Sart \\ Tilman, Belgium \\ ${ }^{1}$ Laboratoire d'Immunologie, Centre de Recherches du CHUM, Hôtel-Dieu, Montreal, Quebec, Canada \\ ${ }^{2}$ Department of Medicine, Division of Experimental Medicine, McGill University, Montreal, Quebec, Canada \\ ${ }^{3}$ Department of Microbiology and Immunology, McGill University, Montreal, Quebec, Canada \\ ${ }^{4}$ Département de Microbiologie et Immunologie, Faculté de Médecine, Université de Montréal, Québec, Canada \\ (Requests for offprints should be addressed to V Geenen; Email: vgeenen@ulg.ac.be) \\ (V Geenen and J-F Poulin contributed equally to this work) \\ (R Cheynier is now at Laboratoire d'Immunologie Cellulaire Antivirale, Institut Pasteur, 28 rue du Dr Roux, F-75015, Paris, France)
}

\begin{abstract}
Although the thymus constitutes a target organ for most protein and steroid hormones, it has been quite difficult to determine the precise control exerted in vivo by the endocrine system upon thymic function. The biological role of the thymus is to ensure the generation of a diversified population of peripheral $\mathrm{T}$ cells able to respond to non-self-antigens but nevertheless tolerant to selfantigens. For a long time, thymic function could not be monitored, as a consequence of the absence of adequate technology to differentiate recent thymic emigrants from naive $\mathrm{T}$ cells. The generation of $\mathrm{T}$ cell receptor (TCR) diversity occurs in the thymus through recombination of gene segments encoding the variable parts of the TCR $\alpha$
\end{abstract}

and $\beta$ chains. During these processes, by-products of the rearrangements are generated in the form of TCR excision circles (TRECs). As these molecules are lost upon further cell division, their quantification is actually considered as a very valuable tool to estimate thymic function. The most appropriate TREC is $\delta$ Rec- $\Psi$ J $\alpha$ TREC or signal joint TREC resulting from $\delta$ Rec- $\Psi \mathrm{J} \alpha$ rearrangement (TCRD deletion) that occurs late during thymopoiesis, before $\mathrm{V} \alpha-\mathrm{J} \alpha$ rearrangement. Here we describe how TREC quantification is a powerful and reliable method to evaluate the impact of hormones and endocrine disorders upon thymic function.

Journal of Endocrinology (2003) 176, 305-311

\section{The place of the thymus in the endocrine system}

During embryonic development, the thymic and inferior parathyroid epithelial rudiments both originate from the endoderm of the third pharyngeal pouch. The thymic epithelial anlage is then colonised by cells of haematopoietic origin (thymocytes) and dendritic cells. Independently, it is invaded by macrophages, also of bone marrow origin. The thymus was considered for a long time to be a component of the endocrine system, but the model of endocrine signalling failed to accurately describe the interactions between the thymic stromal network and developing $\mathrm{T}$ lymphocytes (thymocytes). The involution of the thymus following hypophysectomy was the first evidence for the role of an important endocrine gland in the control of the immune system (Smith 1930). Aside from their endocrine and metabolic functions, antehypophysial and neurohypophysial hormones exert trophic actions on thymus and $\mathrm{T}$ cell development (extensively reviewed in Besedowsky \& Del Rey 1996, Savino \& Dardenne 2000, Berczi 2001). Despite strong evidence indicating regulation of haematopoiesis by growth hormone (GH) (Blazar et al. 1995, Golde \& Cline 1977, Golde et al. 1977, Tian et al. 1998), it remains to be found whether these GH effects are mediated through either modulation of proliferation, activation or survival of 
haematopoietic cells. Interestingly, $\mathrm{GH}$ administration increases thymic volume and density in HIV-infected patients (Napolitano et al. 2002). Moreover, GH-induced increase in thymic mass was associated with an increase in naive $\mathrm{T}$ cells. Combined with the fact that discontinuation of GH therapy led to the recurrence of thymic atrophy, this strongly suggests that thymopoiesis is enhanced by GH treatment (Napolitano et al. 2002). Although GH receptor is detected on a variety of bone marrow-derived cells, most of the effects of $\mathrm{GH}$ on the thymus result from a paracrine action of $\mathrm{GH}-$ dependent insulin-like growth factor-I (Kecha et al. 2000).

Involution of the thymus is observed in experimentally induced hypothyroidism (Fabris 1973, Abou-Rabia \& Kendall 1994). Thymic hyperplasia and intrathymic expression of thyrotrophin receptor have been observed in patients with Graves' disease (Paschke \& Geenen 1995, Murakami et al. 1996).

The impact of steroid hormones on thymic function has also been richly documented. Receptors for glucocorticoids, gonadal steroids and vitamin D are expressed on both thymic epithelial cells and thymocytes. Fluctuation in androgen levels leads to striking changes in thymus weight, cellularity and cell composition. The thymus of male mice is enlarged after orchidectomy or under conditions of defective androgen action (Greenstein et al. 1987). Androgen receptors are expressed by thymic epithelial cells and mediate androgen action on $\mathrm{T}$ cell development (reviewed in Olsen \& Kovacs 1996, Olsen et al. 2001). By 1936, Selye had already observed the marked involution of the thymus and adrenal hypertrophy after severe injury (Selye 1936). Beyond the well-established pro-apoptotic effects of glucocorticoids on thymocytes (Cidlowski et al. 1996), the tight control of immune function and thymopoiesis by the corticotroph axis has been evidenced in physiological conditions and inflammatory disorders (reviewed in Chrousos 2000, Webster et al. 2002).

\section{Physiology of the thymus}

The prominent role of the thymus in $\mathrm{T}$ cell generation (thymopoiesis) was demonstrated by pioneering studies conducted by Miller in the early 1960s (Miller 1961). The critical role of the thymus in the establishment of central $\mathrm{T}$ cell self-tolerance by clonal deletion (negative selection) was evidenced more recently (Kappler et al. 1987, Kisielow et al. 1988, Nossal 1994). The integration of the thymus in endocrine physiology did not completely vanish, however, and the primary lymphoid organ is crucially located at the crossroad between the major systems of cell-to-cell communication, the neuroendocrine and immune systems. Through transcription of neuroendocrine genes in the thymus stromal network and expression of cognate receptors by immature $\mathrm{T}$ cells, the neuroendocrine system regulates early $\mathrm{T}$ cell differenti- ation (reviewed in Geenen et al. 1999, 2003). Glucocorticoids also are synthesised in thymic epithelium and are able to impact on thymocyte development (reviewed in Ashwell et al. 2000). The processing of neuroendocrine precursors in the thymus is not coupled to classical secretion but involves constitutive pathways for membrane targeting and presentation by major histocompatibility complex (MHC) proteins (Robert et al. 1992, Martens et al. 1996a, Vanneste et al. 1997). Neuroendocrine selfantigens derive from the processing of precursors dominantly expressed in the thymus and usually correspond to peptide sequences highly conserved during evolution. According to the theory of clonal selection, thymic MHC presentation of neuroendocrine self-antigens would be responsible for the establishment of central immune selftolerance of neuroendocrine principles (Martens et al. 1996b, Geenen et al. 1999, 2003).

Nowadays, the very complex process of $\mathrm{T}$ cell generation and differentiation may be summarised as follows. From the primary sites of haematopoiesis (embryonic yolk sac, fetal liver, then bone marrow), $\mathrm{T}$ cell progenitors migrate into the thymus and intensively proliferate in the thymic outer cortex. Then, intimate contacts with thymic epithelial and nurse cells promote interleukin-7 synthesis and activate recombination activating genes (RAG1 and RAG2) (Fugmann et al. 2000, Huang et al. 2001). RAG-catalysed generation of $\mathrm{T}$ cell diversity in the thymus occurs through random recombination of gene segments encoding the variable part of the $\mathrm{T}$ cell antigen receptor (TCR) $\alpha$ and $\beta$ chains. TCR recombination by pre- $\mathrm{T}$ cells constitutes a pivotal event because, among the huge number of possible combinations, many of them are able to recognise self-antigens presented by thymic MHC proteins. This negative selection represents the massive deletion of $\mathrm{T}$ cell clones expressing self-reactive TCRs. This process is extremely powerful since, from $100 \mathrm{~T}$ cell progenitors, only one or two $\mathrm{T}$ cells will leave the thymus in a state of self-tolerance, competence and potential activity against non-self-antigens (Scollay 1992). Thus, through a continuous presentation of constant self-antigens to thymocytes that are stochastically rearranging TCR gene segments, the physiological function of the thymus is to ensure the generation of a diverse repertoire of TCRs that are self-tolerant. In addition, the thymus is responsible for the generation of antigen-specific regulatory $\mathrm{T}$ cells that are able to inhibit in the periphery the self-reactivity of $\mathrm{T}$ cells having escaped the thymus-deletion censorship (Heddon \& Mason 2000).

\section{Generation of $T$ cell diversity in the thymus through random TCR gene recombination}

Mature T cells are characterised by their TCR able to recognise specific peptides presented by MHC class I or class II molecules. In order to respond to any particular 
antigen likely to be encountered, the peripheral $\mathrm{T}$ cell population must be highly diverse. This huge heterogeneity, which is not encoded in the germ-line, is generated during $\mathrm{T}$ cell differentiation in the thymus. In this organ, $\mathrm{T}$ cell progenitors undergo a series of developmental events that can be monitored by membrane expression of cluster differentiation (CD) antigens. During $\alpha \beta$ (and $\gamma \delta$ ) $\mathrm{T}$ cell maturation, the juxtaposition of various gene segments leads to the generation of TCRA and TCRB chains (TCRG and TCRD). The antigen-recognising variable domains of TCR $\alpha$ and $\beta$ chains are encoded by combinations of variable $(\mathrm{V})$, diversity $(\mathrm{D})$, and joining $(\mathrm{J})$ gene segments (TCR $\beta$ chains), or $\mathrm{V}$ and $\mathrm{J}$ gene segments (TCR $\alpha$ chains). $\mathrm{V}(\mathrm{D}) \mathrm{J}$ recombination is initiated by the recognition of recombination signal sequences (RSSs) that flank the coding segments. RSSs consist of conserved heptamer (CACAGTG) and nonamer (ACAAAAACC) sequences separated by a less conserved spacer of 12 or $23 \mathrm{bp}$. During maturation, pre- $\mathrm{T}$ cells transiently express the RAG1 and RAG2 genes in order to fuse together V, (D) and J segments. Two successive waves of RAG1 and RAG2 expression coincide with TCRB and TCRA chain rearrangements. RAG-1 and RAG-2 cooperate to recognise the RSSs and introduce hair-pinned site-specific cleavages at the signal-coding borders of a given pair of coding segments. Fusion between distinct V, (D) and J segments leads to a vast array of different TCR $\beta$ chain nucleotide sequences. While this contributes in generating diversified TCR $\alpha$ and $\beta$ chains, a greater diversification is achieved by the addition of $\mathrm{N}$ and $\mathrm{P}$ nucleotides that further broaden this pool. In fact, terminal deoxynucleotide transferase randomly incorporates deoxynucleotides at the junction of segments as they rearrange ( $\mathrm{N}$ nucleotides). Moreover, the end-loop structure resulting from dsDNA break initiation will be further cleaved, leading to the creation of 'sticky-ends' that, once filled, will result in the insertion of palindromic sequences ( $\mathrm{P}$ nucleotides) between rearranged segments. These two events dramatically increase TCR diversity. During any rearrangement process, the DNA located between the two RSSs is circularised, resulting in the formation of an extrachromosomal circular excision product containing the two ligated RSSs. These TCR rearrangement excision circles (TRECs) are stable, are not duplicated during mitosis, and are thus 'diluted-out' with each cell division. A common requirement for productive rearrangement of the TCRA locus is the deletion of the TCRD locus that it encompasses. Deletion of TCRD is an important step during $\mathrm{T}$ cell differentiation and is a sign of the definitive commitment of thymocytes to the $\alpha \beta \mathrm{T}$ lineage. This deletion mainly occurs through specific rearrangement of $\delta \mathrm{Rec}$ and $\Psi \mathrm{J} \alpha$, leading to the generation of a specific TREC - i.e. the signal joint (sj) TREC or $\delta$ Rec- $\Psi$ J $\alpha$ TREC - that can be observed in $\sim 70 \%$ of $\alpha \beta \mathrm{T}$ cells (De Villartay et al. 1988, Verschuren et al. 1997) (Fig. 1). TRECs are stable during a long period, as they have been detected in 41-year thymectomised patients (Sempowski et al. 2001). A maximum of two sjTRECs can be present within one $\alpha \beta \mathrm{T}$ cell if the corresponding rearrangement event occurs in both alleles and if the cell does not proliferate following this rearrangement. TRECs are exported from the thymus to the periphery within recent thymic emigrants (RTEs). However, it was reported that the TCR $\delta$ locus could be excised through other recombination events that will not generate an sjTREC molecule (Veschuren et al. 1997). Therefore, peripheral blood quantification of sjTREC frequencies leads to an underestimation of the real frequency of RTEs. Nonetheless, it provides an unequivocal way to estimate the blood concentration of RTEs and thus, evaluate the magnitude of thymic function. Thus, TREC level in the periphery reflects RTE numbers and is largely accepted as a surrogate marker for thymic function (Kong et al. 1999).

In a recent paper, Hazenberg et al. (2000) suggested that TREC concentration should be utilised carefully to estimate thymic function as it can be affected by events occurring in the periphery such as $\mathrm{T}$ cell proliferation. So, data of TREC quantification should be cautiously interpreted in particular conditions such as during immune reconstitution following bone marrow transplantation or during HIV infection. However, in healthy individuals, only homeostatic naive $\mathrm{T}$ cell proliferation is likely to significantly affect peripheral $\mathrm{T}$ cell TREC content, as antigen-induced $\mathrm{T}$ cell proliferation only affects memory $\mathrm{T}$ cells and thus does not affect the RTE population. Different techniques are employed to measure TREC concentrations, such as real-time PCR, quantitative competitive PCR (Douek et al. 1998), and PCR-ELISA (Al-Harthi et al. 2000). Also, measurement units of TREC concentration vary, including TRECs $/ 10^{6}$ peripheral blood mononuclear cells, TRECs per CD45RA ${ }^{+} \mathrm{T}$ cell, TRECs/ $\mu \mathrm{g}$ DNA of $\mathrm{T}$ cells, and TRECs $/ 10^{5} \mathrm{CD}^{+}$ $T$ cells.

\section{Age-related evolution of sjTREC}

Since the major part of thymocyte proliferation and expansion occurs before this TREC is formed, the sjTREC or $\delta$ Rec- $\Psi$ J $\alpha$ TREC is a very appropriate choice to reflect thymopoiesis (Douek et al. 1998). Therefore, quantification of the sjTREC frequency was selected in our studies. A two-step multiplex real-time PCR was used to quantify sjTRECs in human individuals. In order to carefully quantify the sjTREC frequency, a multiplex nested real-time quantitative PCR was performed on blood samples. In the first step, both the sjTREC molecule and a fragment of the $\mathrm{CD} 3 \gamma$ chain were amplified, allowing cell quantification in the sample as described by J-F Poulin, M Sylvestre, P Champagne, M-L Dion, N Kettaf, A Dumont, M Lainesse, P Fontaine, D-C Roy, C Perreault, R-P Sékaly \& R Cheynier (unpublished observations). In order to stay in the logarithmic linear phase of 


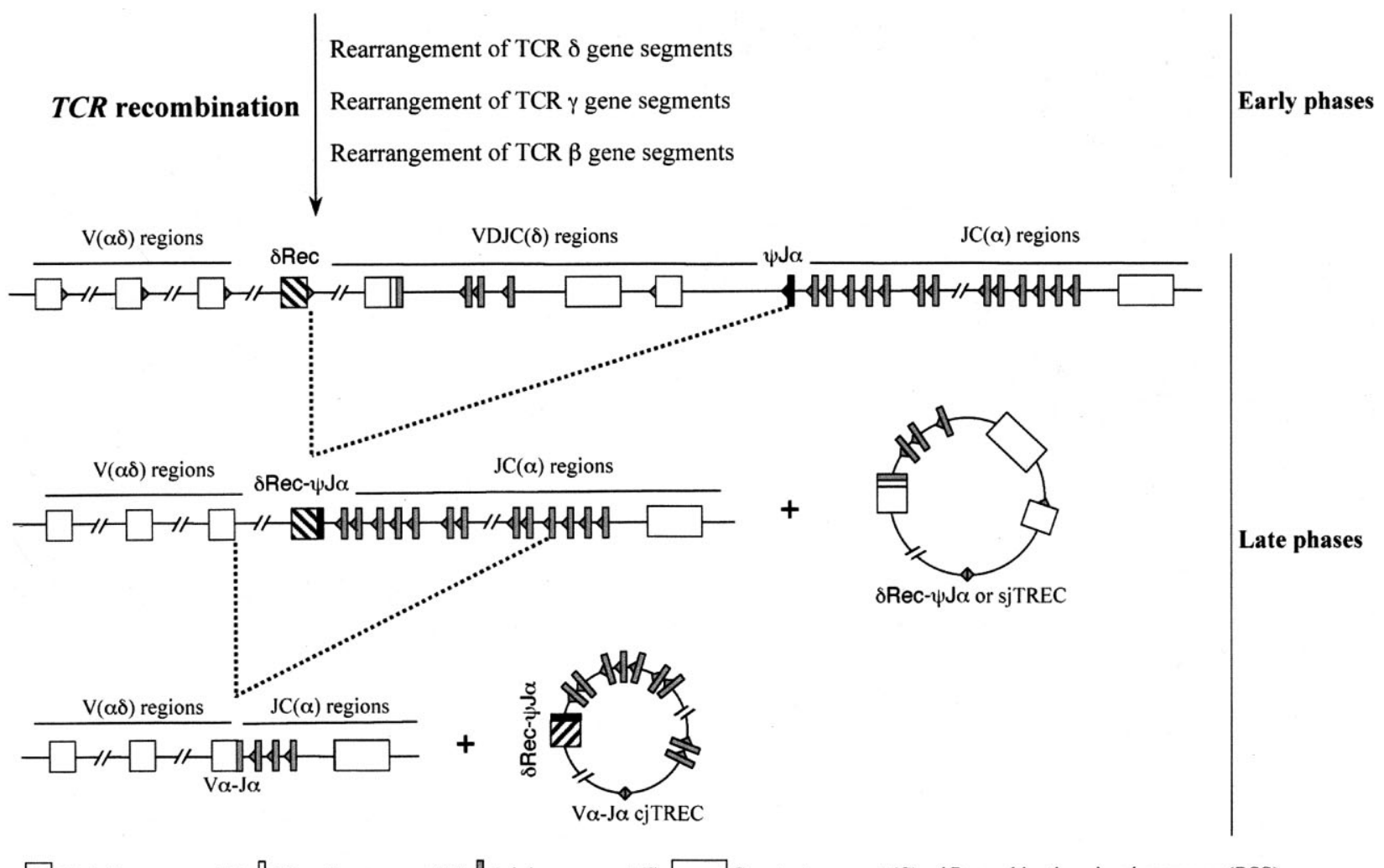

Variable segment (V) D Diversity segment (D) \Joining segment (J)

Constant segment (C) $\triangleleft$ Recombination signal sequence (RSS)

Figure 1 Schematic model of recombination processes leading to sjTREC formation. TCRD deleting elements, $\delta$ Rec- $\Psi$ J $\alpha$, flank the whole TCRD locus. The $\delta$ Rec- $\Psi$ J $\alpha$ rearrangement deletes the TCRD genes and forms an sjTREC (also called $\delta$ Rec- $\Psi$ J $\alpha$ TREC) as it is generated from RAG action by the ligation of the RSS sequences flanking $\delta$ Rec- $\Psi J \alpha$ gene segments. The $\delta$ Rec- $\Psi$ J $\alpha$ sequences remaining in the recombined genome are excised later in most of $\alpha \beta$ T cells during the TCR $\alpha$ chain recombination, and will be found in a V $\alpha$-J $\alpha$ coding joint (cj) TREC (Douek et al. 1998).

the PCR for both amplicons, the first step of amplification was only performed for 22 cycles. The second part of the nested amplification was performed using LightCycler technology (Roche), allowing the quantification of both the sjTREC and the number of cells (as half of the CD3 $\gamma$ copy number) initially present in each sample. These quantifications were based on the amplification of a plasmid reference standard containing both sjTREC and CD3 $\gamma$ templates. For each sample, a precise number of sjTREC copies/100 000 cells can be deduced.

Through this methodology, sjTREC concentration was determined in 41 subjects ranging from 1 to 83 years old. As shown in Fig. 2, sjTREC concentration exponentially decreases with a half-life of 19.62 years. In the population sample, no significant difference appears in the number of sjTRECs $/ 100000$ cells between the 1-10 year $(483 \pm 108$ S.E.M., $n=8)$ and the 11-40 year groups (354 $\pm 77, n=16)$ (Fig. 3). However, a very significant difference $(P<0 \cdot 001)$ exists between the $10-40$ year and the $41-60$ year groups $(65 \pm 27, n=10)$. This decrease remains significant $(P<0 \cdot 001)$ between the $41-60$ year and the $61-80+$ year $(20 \pm 5, n=7)$ groups. In our hands, a correlation with gender was not found although such a correlation was previously reported (Pido-Lopez et al. 2001).

\section{Thymic function in clinical conditions and in the elderly}

In $\mathrm{T}$ cell depleting diseases such as HIV infection, treatment with highly active anti-retroviral therapy (HAART) induces a rapid increase in the numbers of detectable TRECs in peripheral cells (Douek et al. 1998, Poulin \& Sekaly 1999, Poulin et al. 1999). Thus, the adult thymus retains a significant thymopoietic function and still generates naive, newly differentiated, and functional $\mathrm{T}$ cells for export to the periphery (Jamieson et al. 1999). Increases in naive $\mathrm{T}$ cells in HIV-infected and HAART-treated patients who had been thymectomised before suggest that naive $\mathrm{T}$ cells may replicate in the periphery (Haynes et al. 1999). Also in immuno-haematologic diseases and 


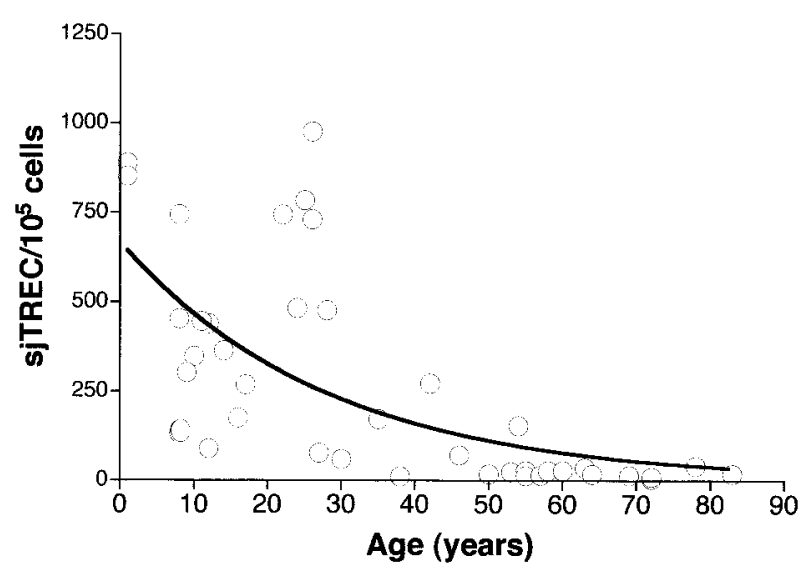

Figure 2 Age-related evolution of sjTREC number per $100000 \mathrm{~T}$ cells in normal subjects $(n=41)$. The number of sjTRECs was measured by real-time PCR and normalised by cell number estimated with genomic CD3 $\gamma$ content measured by real-time PCR of the same sample. sjTREC concentration decreases with age in an exponential way $(P=0 \cdot 0014)$.

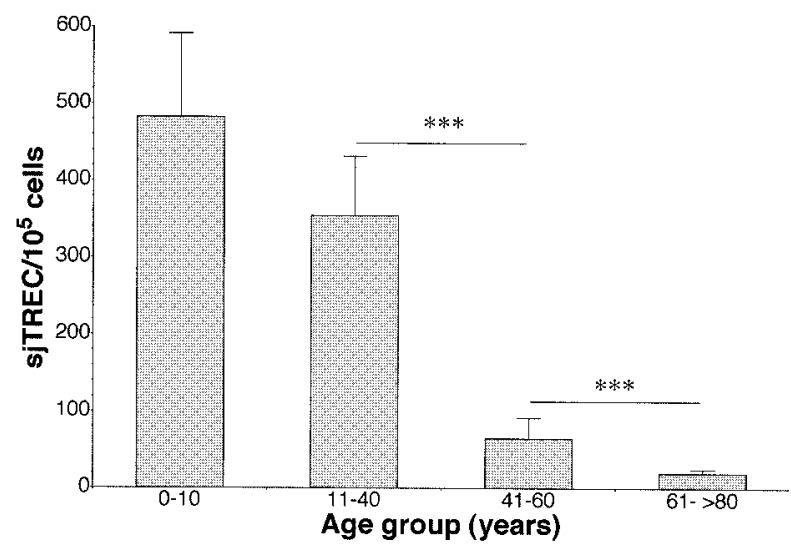

Figure 3 Number of sjTRECs per 100000 T cells in different age classes. Statistical significance of differences has been determined with Student's t-test $\left({ }^{* *} P<0 \cdot 001\right)$.

malignancies, rapid $\mathrm{T}$ cell regeneration after high-dose chemotherapy requires a residual thymic function (Mackall et al. 1995). An efficient thymic function was shown to be associated with a favourable immune reconstitution after cord blood stem cell transplantation (Talvensaari et al. 2002). In patients with severe combined immunodeficiency, stem-cell transplantation (Patel et al. 2000) or gene therapy (Hacein-Bey-Abina et al. 2002) was followed by an increase from undetected levels in the number of $\mathrm{T}$ cells containing sjTRECs. Some thymic dysfunction in $\mathrm{T}$ cell generation was also recently suggested in rheumatoid arthritis (Koetz et al. 2000).

For a long time it has been assumed that the thymic function gradually decreases after puberty, in parallel with the progressive enrichment of the thymic stroma in adipose cells (thymic adipose 'involution'). By 18 years of age, the periphery was thought to be seeded with a complete repertoire of antigen-reactive $\mathrm{T}$ cells (Simpson et al. 1975). In recent years, more and more data have contradicted this quite dogmatic view and provided demonstrative evidence that the adult thymus remains active late in life and generates functional $\mathrm{T}$ cells for the peripheral lymphoid repertoire (Aspinall et al. 2002). In accord with those studies, as shown in Fig. 3, a significant number of sjTRECs are measured even in adults between 61 and more than 80 years of age. The persistence of thymopoiesis and generation of TCR diversity has important implications for the problem of immunosenescence. Indeed, ageing of the immune system is associated with increased morbidity and mortality from infectious diseases, decreased tumoral immunity with higher prevalence of cancers, as well as a decrease of immune self-tolerance leading to some autoimmune diseases (Pawelec et al. 2002). The restoration of thymic function in ageing and in various disorders seems thus to be an important objective in the elderly, in AIDS and in a series of haematooncological diseases. Since the thymic stroma expresses receptors for a number of hormones (reviewed in Kelley et al. 1986, Savino \& Dardenne 2000, Murphy \& Longo 2000), ensuring an adequate endocrine equilibrium should be important for maintaining thymic functions, i.e. generation of $\mathrm{T}$ cells with a diverse but self-tolerant TCR repertoire. Obviously, quantification of thymic $\mathrm{T}$ cell generation through TREC methodology now constitutes a very important parameter to measure in studies aiming to evaluate the consequence of neuroendocrine ageing (Lamberts et al. 1997) and diseases upon immune function, as well as the benefits expected to follow restoration of hormonal equilibrium.

\section{Acknowledgements}

These studies are supported by the Research Special Fund of Liege University, by Fondation Léon Fredericq, by the Fund for Scientific Medical Research of Belgium (FRSM grant no. 3.4574.02), by Fondation Vaugrenier for Tolerance Research, and by the Belgian Federation against Cancer. V G is Research Director of the Belgian NFSR; I $\mathrm{H}$ is supported by FRIA; J-F P is a recipient of a CHIR doctoral research award.

\section{References}

Abou-Rabia N \& Kendall MD 1994 Involution of the rat thymus in experimentally induced hypothyroidism. Cell and Tissue Research 277 447-455.

Al-Harthi L, Marchetti G, Steffens CM, Poulin J, Sekaly R \& Landay A 2000 Detection of T cell receptor circles (TRECs) as biomarkers for de novo $\mathrm{T}$ cell synthesis using a quantitative polymerase chain reaction-enzyme linked immunosorbent assay (PCR-ELISA). Journal of Immunological Methods 237 187-197. 
Ashwell JD, Lu FWM \& Vecchio MS 2000 Glucocorticoids in T cell development and function. Annual Review of Immunology 18 304-348.

Aspinall R, Andrew D \& Pido-Lopez J 2002 Age-associated changes in thymopoiesis. Springer Seminars in Immunopathology 24 87-101.

Berczi I 2001 Neuroimmune biology - an introduction. In New Frontier of Biology Series, vol 1, pp 3-45. Eds I Berczi \& RM Gorczynski. Amsterdam, The Netherlands: Elsevier.

Besedowsky HO \& Del Rey A 1996 Immune-neuro-endocrine interactions: facts and hypotheses. Endocrine Reviews 17 64-102.

Blazar BR, Brennan CA, Broxmeyer HE, Shultz LD \& Vallera DA 1995 Transgenic mice expressing either bovine growth hormone (bGH) or human $\mathrm{GH}$ releasing hormone (hGRH) have increased splenic progenitor cell colony formation and DNA synthesis in vitro and in vivo. Experimental Hematology 23 1397-1406.

Chrousos GP 2000 The stress response and immune function; clinical implications. The 1999 Novera H Spector Lecture. Annals of the New York Academy of Sciences 917 38-67.

Cidlowski JA, King KL, Evans-Storms RB, Montague JW, Bortner CD \& Hughes FM Jr 1996 The biochemistry and molecular biology of glucocorticoid-induced apoptosis in the immune system. Recent Progress in Hormone Research 51 457-490.

De Villartay JP, Hockett RD, Coran D, Korsmeyer SJ \& Cohen DI 1988 Deletion of the human T-cell receptor $\delta$ gene by a site-specific recombination. Nature 335 170-174.

Douek DC, McFarland RD, Keiser PH, Gage EA, Massey JM, Haynes BF, Polis MA, Haase AT, Feinberg MB, Sullivan JL et al. 1998 Changes in thymic function with age and during treatment of HIV infection. Nature 396 690-695.

Fabris N 1973 Immunodepression in thyroid-deprived animals. Clinical and Experimental Immunology 15 601-611.

Fugmann SD, Lee AI, Schockett PE, Villey IJ \& Schatz DG 2000 The RAG proteins and V(D)J recombination: complexes, ends and transposition. Annual Review of Immunology 18 495-522.

Geenen V, Kecha O, Brilot F, Charlet-Renard C \& Martens H 1999 The thymic repertoire of neuroendocrine self-antigens: biological role in $\mathrm{T}$ cell selection and pharmacological implications. Neuroimmunomodulation 6 115-125.

Geenen V, Brilot F, Hansenne I, Kecha-Kamoun O \& Martens H 2003 Thymus and T cells. Encyclopedia of Neuroscience, edn 3. Eds G Adelman \& BH Smith. New York: Elsevier (In Press).

Golde DW \& Cline MJ 1977 Hormonal interactions with hematopoietic cells in vitro. Transplantation Proceedings 10 95-97.

Golde DW, Bersch N \& Li CH 1977 Growth hormone: species-specific stimulation of erythropoiesis in vitro. Science 196 1112-1113.

Greenstein BD, Fitzpatrick FT, Kendall MD \& Wheeler MJ 1987 Regeneration of the thymus in old male rats treated with a stable analogue of LHRH. Journal of Endocrinology 112 345-350.

Hacein-Bey-Abina S, Le Deist F, Carlier F, Bouneaud C, Hue C, De Villartay JP, Thrasher AJ, Wulffraat N, Sorensen R, Dupuis-Girod $\mathrm{S}$ et al. 2002 Sustained correction of X-linked severe combines immunodeficiency by ex vivo gene therapy. New England Journal of Medicine 346 1185-1193.

Haynes BF, Hale LP, Weinhold KJ, Patel DD, Liao HX, Bressler PB, Jones DM, Demarest JF, Gebhard-Mitchell K, Haase AT et al. 1999 Analysis of the adult thymus in reconstitution of T lymphocytes in HIV-1 infection. Journal of Clinical Investigation 103 453-460.

Hazenberg MD, Otto SA, Cohen Stuart JW, Verschuren MC, Borleffs JC, Boucher CA, Coutinho RA, Lange JM, Rinke de Wit TF, Tsegaye A et al. 2000 Increased cell division but not thymic dysfunction rapidly affects the $\mathrm{T}$-cell receptor excision circle content of the naive T cell population in HIV-1 infection. Nature Medicine 6 1036-1042.

Heddon B \& Mason D 2000 The third function of the thymus. Immunology Today 21 95-99.
Huang J, Durum SK \& Muegge K 2001 Cutting edge: histone acetylation and recombination at the TCR gamma locus follows IL-7 induction. Journal of Immunology 167 6073-6077.

Jamieson BD, Douek DC, Killian S, Hultin LE, Scripture-Adams DD, Giorgi JV, Marelli D, Koup RA \& Zack JA 1999 Generation of functional thymocytes in the human adult. Immunity 10 569-575.

Kappler JW, Roehm N \& Marrack P 1987 T-cell tolerance by clonal elimination in the thymus. Cell $49273-280$.

Kecha O, Brilot F, Martens H, Franchimont N, Renard C, Greimers R, Defresne MP, Winkler R \& Geenen V 2000 Involvement of insulin-like growth factors in early T cell development: a study using fetal thymic organ cultures. Endocrinology 141 1209-1217.

Kelley KW, Brief S, Westly HJ, Novakofski J, Bechtel PJ, Simon J \& Walker EB $1986 \mathrm{GH}_{3}$ pituitary adenoma cells can reverse thymic aging in rats. PNAS $\mathbf{8 3} 5663-5667$.

Kisielow P, Blüthmann H, Staerz D, Steinmetz M \& Von Boehmer H 1988 Tolerance in T-cell receptor transgenic mice involves deletion of nonmature CD4+8+ thymocytes. Nature 333 742-746.

Koetz K, Bryl E, Spickschen K, O’Fallon WM, Goronzy J \& Weyand CM $2000 \mathrm{~T}$ cell homeostasis in patients with rheumatoid arthritis. PNAS 97 9203-9208.

Kong FK, Chen CL, Six A, Hockett RD \& Cooper MD 1999 T-cell receptor deletion circles identify recent thymic emigrants in the peripheral T cell pool. PNAS 96 1536-1540.

Lamberts SWJ, van den Beld AW \& van der Lely AJ 1997 The endocrinology of aging. Science 278 419-424.

Mackall CL, Fleisher TA, Brown MR, Andrich MP, Chen CC, Feuerstein IM, Horowitz ME, Magrath IT, Shad AT, Steinberg SM et al. 1995 Age, thymopoiesis, and CD4+ T-lymphocyte regeneration after intensive chemotherapy. New England Journal of Medicine 332 143-149.

Martens H, Magrange B, Robert F, Charlet C, De Groote D, Heymann D, Godard A, Soulillou JP, Moonen G \& Geenen V 1996a Cytokine production by human thymic epithelial cells: control by the immune recognition of the neurohypophysial self-antigen. Regulatory Peptides 67 39-45.

Martens H, Goxe B \& Geenen V 19966 The thymic repertoire of neuroendocrine-related self-antigens: physiological implications in T-cell life and death. Immunology Today 17 312-317.

Miller JFAP 1961 Immunological function of the thymus. Lancet 2 748-749.

Murakami M, Hosoi Y, Negishi T, Kamiya Y, Yamada M, Iriuchijima T, Yokoo H, Yoshida Y \& Mori M 1996 Thymic hyperplasia in patients with Graves' disease. Identification of thyrotropin receptors in human thymus. Journal of Clinical Investigation 98 2228-2234.

Murphy WJ \& Longo DL 2000 Growth hormone as an immunomodulating therapeutic agent. Immunology Today 21 211-213.

Napolitano LA, Lo JC, Gotway MB, Mulligan K, Barbour JD, Schmidt D, Grant RM, Halvorsen RA, Schambelan M \& McCune JM 2002 Increased thymic mass and circulating naive CD4 T cells in HIV-1-infected adults treated with growth hormone. AIDS 16 1103-1111.

Nossal GJV 1994 Negative selection of thymocytes. Cell 76 229-239.

Olsen NJ \& Kovacs WJ 1996 Gonadal steroids and immunity. Endocrine Reviews 17 363-384.

Olsen NJ, Olson G, Viselli SM, Gu X \& Kovacs WJ 2001 Androgen receptors in thymic epithelium modulate thymus size and thymocyte development. Endocrinology 142 1278-1283.

Paschke R \& Geenen V 1995 Messenger RNA expression for a TSH receptor variant in the thymus of a two-year-old child. Journal of Molecular Medicine 73 577-580.

Patel DD, Gooding ME, Parrott RE, Curtis KM, Haynes BF \& Buckley RH 2000 Thymic function after hematopoietic stem-cell transplantation for the treatment of severe combined immunodeficiency. New England Journal of Medicine 342 1325-1332. 
Pawelec G, Barnett Y, Forsey R, Frasca D, Globerson A, McLeod J, Caruso C, Franceschi C, Fulop T, Gupta S et al. 2002 T cells and aging, January 2002 update. Frontiers in Biosciences 7 d1056-d1183.

Pido-Lopez J, Imami N \& Aspinall R 2001 Both age and gender affect thymic output: more recent thymic migrants in female than males as they age. Clinical and Experimental Immunology 125 409-413.

Poulin JF \& Sekaly RP 1999 Function of the thymus in HIV-infected adults. Journal of the American Medical Association 282219

Poulin JF, Viswanathan MN, Harris JM, Kumanduri KV, Wieder E, Rinquette N, Jenkins M, McCune JM \& Sekaly RP 1999 Direct evidence for thymic function in adult humans. Journal of Experimental Medicine 190 479-486.

Robert FR, Martens H, Cormann N, Benhida A, Schoenen J \& Geenen V 1992 The recognition of hypothalamo-neurohypophysial functions by developing T cells. Developmental Immunology 2 131-140.

Savino W \& Dardenne M 2000 Neuroendocrine control of thymus physiology. Endocrine Reviews 21 412-443.

Scollay R 1992 T lymphocytes. In Encyclopedia of Immunology, edn 1, pp 1473-1475. Eds IM Roitt \& PJ Delves. London: Academic Press.

Selye H 1936 Thymus and adrenals in the response of the organism to injuries and intoxication. British Journal of Experimental Pathology 17 234-247.

Sempowski G, Thomash J, Gooding M, Hale L, Edwards L, Ciafoni E, Sanders D, Massey J, Douek D, Koup R et al. 2001 Effect of thymectomy on human peripheral blood $\mathrm{T}$ cell pools in myasthenia gravis. Journal of Immunology 166 2808-2817.

Simpson JG, Gray ES \& Beck JS 1975 Age involution in the normal human adult thymus. Clinical and Experimental Immunology 19 $261-265$.
Smith PE 1930 Effects of hypophysectomy upon the involution of the thymus in the rat. Anatomical Recordings 47 119-129.

Talvensaari K, Clave E, Douay C, Rabian C, Garderet L, Busson M, Garnier F, Douek D, Gluckman E, Charron D et al. 2002 A broad T-cell repertoire diversity and an efficient thymic function indicate a favorable long-term immune reconstitution after cord blood stem cell transplantation. Blood 99 1458-1464.

Tian ZG, Woody MA, Sun R, Welniak LA, Raziuddin A, Funakoshi S, Tsarfaty G, Longo DL \& Murphy WJ 1998 Recombinant human growth hormone promotes hematopoietic reconstitution after syngeneic bone marrow transplantation in mice. Stem Cells 16 193-198.

Vanneste Y, Ntodou Thome A, Vandersmissen E, Charlet C, Franchimont D, Martens H, Lhiaubet AM, Schimpff RM, Rostene W \& Geenen V 1997 Identification of neurotensin-related peptides in human thymic epithelial cell membranes and relationship with major histocompatibility complex class I molecules. Journal of Neuroimmunology 76 161-166.

Verschuren MC, Wolvers-Tettero IL, Breit TM, Noordzij J, van Wering ER \& van Dongen JJ 1997 Preferential rearrangements of the $\mathrm{T}$ cell receptor-delta-deleting elements in human $\mathrm{T}$ cells. Journal of Immunology 158 1208-1216.

Webster JL, Tonelli L \& Sternberg EM 2002 Neuroendocrine regulation of immunity. Annual Review of Immunology 20 $125-163$.

Received 24 September 2002 Accepted 4 December 2002 